\title{
Physical Simulation Experimental Technology and Mechanism of Water Invasion in Fractured-Porous Gas Reservoir: A Review
}

\author{
Mengfei Zhou ${ }^{1,2, *} \mathbb{D}$, Xizhe $\mathrm{Li}^{3, *}$, Yong $\mathrm{Hu}^{3, *}$, Xuan $\mathrm{Xu}^{3}$, Liangji Jiang ${ }^{3}$ and Yalong $\mathrm{Li}^{1,2}$ \\ 1 School of Engineering Science, University of Chinese Academy of Sciences, Beijing 100049, China; \\ liyalong16@mails.ucas.ac.cn \\ 2 Institute of Porous Flow and Fluid Mechanics, Chinese Academy of Sciences, Langfang 065007, China \\ 3 Research Institute of Petroleum Exploration \& Development, Beijing 100083, China; \\ xuxuan69@petrochina.com.cn (X.X.); jiangliangj69@petrochina.com.cn (L.J.) \\ * Correspondence: zhoumengfei19@mails.ucas.ac.cn (M.Z.); lxz69@petrochina.com.cn (X.L.); \\ huy69@petrochina.com.cn (Y.H.)
}

check for updates

Citation: Zhou, M.; Li, X.; Hu, Y.; Xu, X.; Jiang, L.; Li, Y. Physical Simulation Experimental Technology and Mechanism of Water Invasion in Fractured-Porous Gas Reservoir: A Review. Energies 2021, 14, 3918. https://doi.org/10.3390/en14133918

Academic Editor: Kun Sang Lee

Received: 29 May 2021

Accepted: 27 June 2021

Published: 30 June 2021

Publisher's Note: MDPI stays neutral with regard to jurisdictional claims in published maps and institutional affiliations.

Copyright: (c) 2021 by the authors. Licensee MDPI, Basel, Switzerland. This article is an open access article distributed under the terms and conditions of the Creative Commons Attribution (CC BY) license (https:// creativecommons.org/licenses/by/ $4.0 /)$

\begin{abstract}
In the development process for a fractured-porous gas reservoir with developed fracture and active water, edge water or bottom water easily bursts rapidly along the fracture to the production well, and the reservoir matrix will absorb water, reducing the gas percolation channel and increasing the gas phase percolation resistance of the reservoir matrix, therefor reducing the stable production capacity and recovery efficiency of the gas reservoir. For this reason, this paper investigates physical simulation experimental technology and mechanisms as reported by both domestic and foreign scholars regarding water invasion in fractured-porous gas reservoirs. In this paper, it is considered that the future trend and focus of water invasion experiments will be to establish a more realistic three-dimensional physical model on the basis of fine geological description, combined with gas reservoir well pattern deployment and production characteristics, and to fully consider the difference between horizontal and vertical water invasion along the reservoir side; at the same time, dynamic parameters such as model pressure field and water saturation field can be obtained in real time. Based on this understanding of the water invasion mechanism of fractured-porous gas reservoirs, we propose the next research direction and the development countermeasures such as water controls, drainage, and dissolved water seals and water locks to combat water invasion in reservoirs, along with the injection of gas to replenish formation energy, etc., so as to slow down and control the influence of water invasion.
\end{abstract}

Keywords: fractured-porous gas reservoir; water invasion mechanism; experimental technique; enhanced gas recovery; development countermeasures

\section{Introduction}

China's annual natural gas output has exceeded 100 million tons of oil equivalent, and natural gas consumption has grown at an average annual rate of $12 \%$ in the past decade, playing a significant role in the country's transition to low-carbon energy [1-10]. Proven reserves of aqueous gas reservoirs account for more than $50 \%$ of conventional natural gas in China, which is the core area of natural gas development to increase production [11]. The significant reduction of gas recovery caused by non-uniform water invasion is a key problem in the development of gas reservoirs with water. The global development of typical gas reservoirs shows that non-uniform water invasion results in productivity reduction as high as $60-80 \%$ for gas wells, and the recovery of water invaded gas reservoirs is generally less than $50 \%$, while that of fractured water invaded gas reservoirs is only $20-45 \%$ [12-19]. Therefore, the development of water-control to improve recovery of gas reservoirs is an important and difficult global issue.

Oil and gas reservoirs consist of a typical porous medium, which generally develops various forms of storage and permeability space, such as pores, fractures and karst 
caves, and the storage and permeability spaces of different reservoirs vary [20]. In order to identify the main channel types of complex porous media in oil and gas reservoirs, Li et al. $[20,21]$ defined the "main channel index" by using the ratio of comprehensive permeability obtained by well test interpretation to matrix permeability obtained by core test (or well logging interpretation), and realized the quantitative division of flow channel types. For porous reservoirs, the index is less than 3 , and matrix pores are the main flow channel. For fractured-porous reservoirs, the index ranges from 3 to 20, and the flow channels are dominated by fractures and supplemented by matrix pores. For fractured reservoirs, the index is greater than 20 , and visible fractures are the only seepage channels. The reservoir rocks of fractured-porous gas reservoirs with water (edge water or bottom water) are generally carbonate rocks and sandstone, its heterogeneity is severe, the main reservoir space is the pore in the matrix, and the main seepage channel is the fracture [22]. In the development process of fractured-porous gas reservoirs with well-developed fractures and active water, edge water or bottom water is easy to burst rapidly along the fracture channel into the production well; at the same time, the reservoir matrix will absorb water, and after thus the gas phase seepage channel will be reduced, increasing the gas phase seepage resistance of the reservoir matrix, reducing the stable production capacity of the gas reservoir and the final recovery degree $[23,24]$. Therefore, understanding the mechanism, realizing risk warnings, and optimizing development technology for water invaded gas reservoirs are essential to improve recovery, and indoor experiments are an important means of solving these problems. Therefore, it is necessary to summarize the current physical simulation experimental technology, mechanisms, and development technology regarding water invasion, thereby presenting the next direction for research. For this reason, this paper investigates the experimental research methods and results of domestic and foreign scholars on water invasion mechanisms in fractured-porous gas reservoirs, and summarizes future research directions, as well as putting forward development countermeasures to improve gas recovery of water invaded gas reservoirs, which is of significance for further study.

\section{Physical Simulation Experimental Technology of Water Invasion in Gas Reservoirs}

\subsection{Microscopic Visualized Physical Simulation Experimental Technology}

In recent years, in view of the problem that the research on underground seepage has been mainly focused on the macro point of view, scholars at home and abroad have paid more and more attention to the micro-seepage mechanism in the process of water invasion, and have carried out a large number of physical simulation studies on the mechanism of water invasion in gas reservoirs, to observe the seepage characteristics in the process of gaswater mutual flooding through visualization, so as to reveal the water invasion mechanism, which lays an important theoretical foundation for improving recovery. In the physical simulation experiment of gas-water mutual flooding using microscopic visualization to reveal the water invasion mechanism, the most important part is the authenticity of the model, i.e., the model can truly reflect the pore throat structure, formation temperature and pressure of rock. Foreign studies in this field began as early as the 1970s, when Davis [25], Mast [26], Wardlaw [27], Morrow [28,29] et al. applied preservatives in the non-test area of glass plate, and then soaked the glass plate in hydrofluoric acid solution for corrosion, thus obtaining an artificial model similar to the pore system of rock in the test area of the glass plate. The earliest model in China appeared in 1984, when Guo et al. [30] developed a microscopic network physical model and a model regeneration technique, and preliminarily studied the fluid distribution and flow state in the microscopic model of different wettability strata by means of a microwave device and optical microphotography for continuous measuring of the ratio of multiphase fluid in a capillary (inner diameter $0.07 \mathrm{~mm}$ ) developed by Lanzhou Division of Fluid Flow Mechanics Research. This capillary network model is single-layer, transparent, and its wettability is controllable and stable. At the same time, a model can be reused many times to keep its various parameters unchanged, which ensures the accuracy and comparison value of the experiment. Qu et al. [31] first 
used foreign methods for reference, using paraffin as preservative and hydrofluoric acid to corrode glass in order to make a transparent pore model, and used this model for gas flooding experiments. Via this experiment, he considered that the uneven distribution of throat size was the root cause of the formation of residual water.

With the development of laser technology, $\mathrm{Yu}$ [32], Wu [33], Zhou [34], Li [35] and Fan [24] et al. obtained the pore structure of rock by casting thin slices, and advanced laser etching technology was used to etch the real pore structure of rock on optical glass plate to make a transparent microscopic gas-water two-phase percolation experimental model for the camera. Due to the application and development of micro-nano CT imaging technology in the characterization of microscopic pore-throat structure of rocks, scholars [36-44] further directly scanned rock samples through $\mathrm{CT}$ to obtain more real images, and extracted the morphology of cracks and holes, then obtaining physical models through laser etching glass. Figure 1 shows the process of building a visual model.

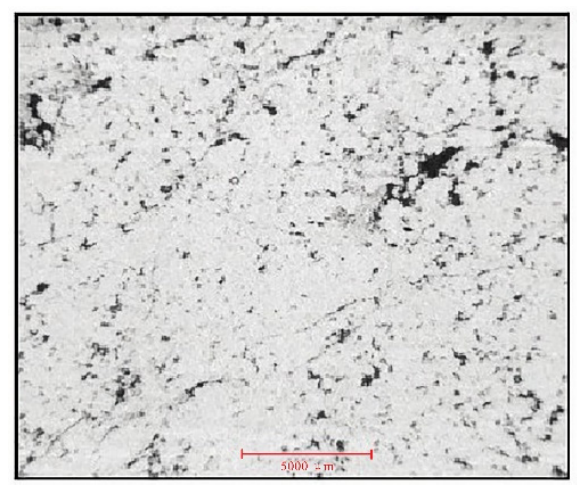

(a)

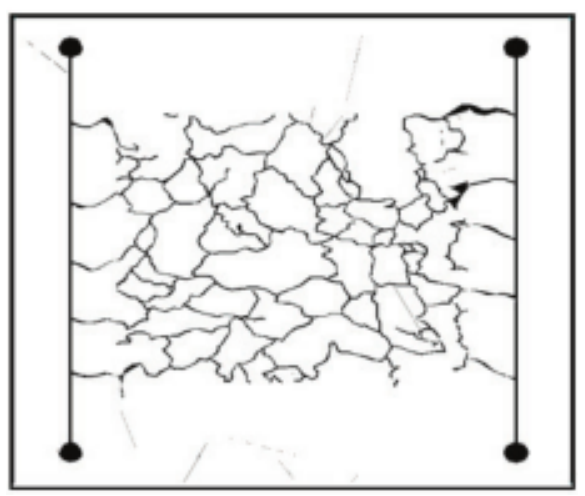

(b)

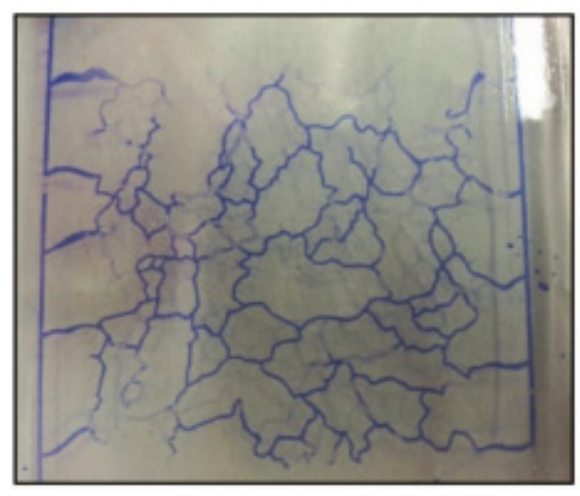

(c)

Figure 1. Visualization model based on CT scan results: (a) CT image of fractured reservoir; (b) CT image extraction model; (c) Visualized physical model of fractured reservoir [37].

Physical models mainly concentrated in the porous or fractured gas reservoir, while the more complex hole and fractured-cavern gas reservoirs are relatively less studied, Fang [45], Ye [46] et al. have made corresponding plate visual physical models according to the main reservoir space characteristics of different types of gas reservoir. The model adopts a "sandwich" structure, the upper and lower layers are glass, and the middle cavity is filled with sand. As shown in Table 1, by simulating the depleted development of edge and bottom water gas reservoirs, the flow path, laws of movement for the water, and gas-water distribution in porous type, fractured type, hole type and fractured-cavern type gas reservoirs are studied in the process of development; therefore, the water invasion rules of different types of gas reservoir are characterized intuitively.

Microfluidic technology is a technology used to study the interaction between fluids at micro- and nano-scales. In oil and gas field development experiments, it is mainly used to study the seepage law of multiphase fluids in microscopic pore-throat structures. The microfluidic chip has good light transmission performance, which makes it easy to be used in seepage visualization experiments [47,48]. Lyu et al. [49] used 3D printing technology to produce a pore-throat microfluidic chip with height $\times$ length $\times$ width $=0.2 \mathrm{~cm} \times 0.8 \mathrm{~cm} \times$ $0.6 \mathrm{~cm}$. As shown in Figure 2, gas-water mutual flooding was carried out under different displacement velocities, so as to observe and record the distribution of gas and water in the pores during displacement. 
Table 1. Simulation of water invasion law in fractured-cavern gas reservoir [45].

\begin{tabular}{|c|c|c|c|}
\hline Model Type & Water Invasion Characteristics & $\begin{array}{c}\text { Water-Free } \\
\text { Recovery Factor/\% }\end{array}$ & $\begin{array}{c}\text { Final Recovery } \\
\text { Degree/\% }\end{array}$ \\
\hline $\begin{array}{l}\text { I: Isolated fractured-cavern } \\
\text { type bottom water gas } \\
\text { reservoir }\end{array}$ & & 62.7 & 70.5 \\
\hline $\begin{array}{l}\text { II: Upper fractured-cavern } \\
\text { type and lower porous type } \\
\text { edge water gas reservoir }\end{array}$ & & 26 & 28 \\
\hline $\begin{array}{l}\text { III: Upper porous type and } \\
\text { lower fractured-cavern type } \\
\text { edge water gas reservoir }\end{array}$ & & 53 & 68 \\
\hline
\end{tabular}

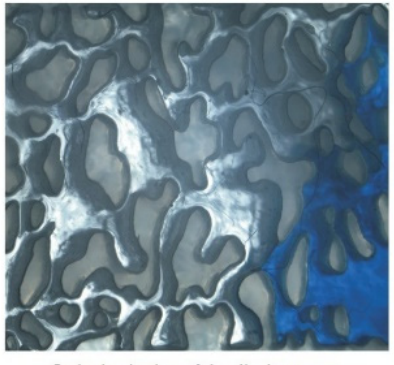

(1) The beginning of the displacement

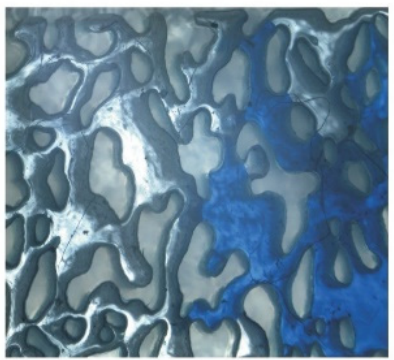

(1) The beginning of the displacement

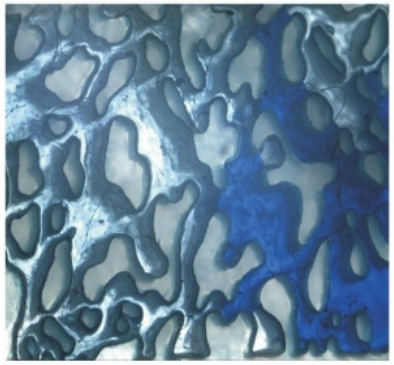

(The beginning of the displacement

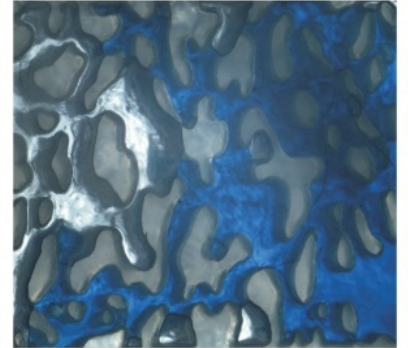

(2) The middle of the displacement (a) The displacement velocity is $0.010 \mathrm{~mL} / \mathrm{min}$

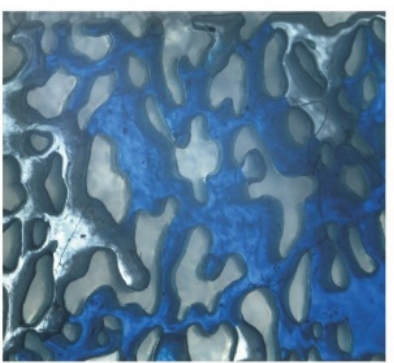

(2) The middle of the displacement (b) The displacement velocity is $0.030 \mathrm{~mL} / \mathrm{min}$

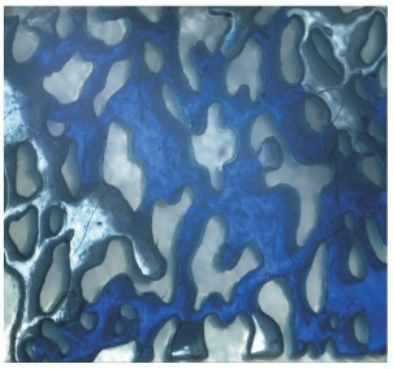

(2) The middle of the displacement

(c) The displacement velocity is 0.050

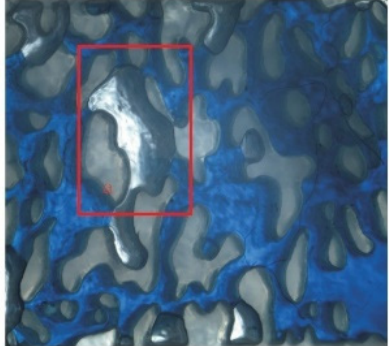

(1)The end of the displacement

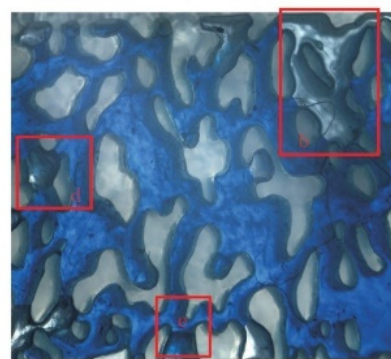

(1)The end of the displacement

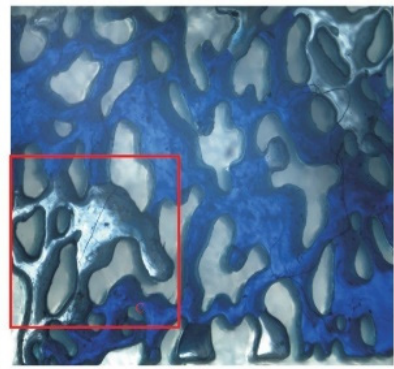

(2) The end of the displacement

Figure 2. Gas and water distribution in the water drive process of a microfluidic chip [49].

The above model is based on the real core, which is limited by the acquisition of the real core pore network structure and the reproduction of the pore throat structure, so it is difficult to completely copy the real core pore network structure. Kong [50] and Li [51] directly sliced the core to obtain a sandstone microscopic model, $3 \mathrm{~cm}$ in length, $2 \mathrm{~cm}$ in width and $0.062 \mathrm{~cm}$ in thickness. Methyl blue is added to the simulated formation water 
to show blue, and oil red is added to the mixed oil to show red. As a result, the water flooding experiment is carried out, and the image of the displacement process is collected by stereoscopic microscope. Nuclear magnetic resonance (NMR) detection technology is a non-destructive core detection technology, which reflects the distribution of fluid in rock pores by detecting the signal of the hydrogen atomic nucleus. At present, the most widely used is $T_{2}$ spectrum and NMR imaging. Nuclear magnetic resonance imaging (MRI) can obtain cross-sectional and three-dimensional images of rock samples, which can be used for water intrusion visualization [52-58].

As shown in Table 2, all the above microscopic visualization experimental methods have realized the visualization of the gas-water seepage process, and the characteristics of actual core pores, throat and fractures have been reproduced through an artificial transparency model, so as to explore the formation mechanism of closed gas in the process of water invasion. However, many scholars [59-61] have confirmed that the rock pore structure under high temperature and high pressure is different from that under conventional conditions, and the water-gas viscosity ratio is smaller under high temperature and high pressure, making it more difficult for water to drive gas. Therefore, there may be some deviation in the understanding obtained by such models. At present, except that the physical model of MRI is the core plug, the physical models of other methods are thin chips, which cannot withstand high pressure. However, MRI cannot obtain the formation of water lock in the pore throat of rock during the water drive gas process; at the same time, its temperature and pressure need to be improved to simulate real gas reservoirs. Therefore, when the research purpose is to obtain the macroscopic gas-water distribution images in the process of water invasion, a MRI method can be adopted, while when the research purpose is to observe the water locking in the pore-throat during the process of water invasion, other methods mentioned above can be adopted.

Table 2. Comparison of experimental models and methods for microscopic visual physical simulation.

\begin{tabular}{|c|c|c|c|c|}
\hline Experimental Model & Research Scholar & Experimental Method & Experiment Condition & Characteristic \\
\hline Etched glass model & $\begin{array}{c}\text { Davis [25], Mast [26], } \\
\text { Wardlaw [27], Morrow } \\
\text { [28,29], Qu [31] et al. }\end{array}$ & $\begin{array}{l}\text { Etch glass with } \\
\text { hydrofluoric acid } \rightarrow \\
\text { Experiment under wide } \\
\text { field projector }\end{array}$ & $\begin{array}{l}\text { Normal pressure and } \\
\text { temperature }\end{array}$ & $\begin{array}{c}\text { It can be observed directly } \\
\text { and is easy to make }\end{array}$ \\
\hline $\begin{array}{l}\text { Physical regeneration } \\
\text { model of capillary } \\
\text { networks }\end{array}$ & Guo [30] et al. & $\begin{array}{l}\text { Several perpendicular } \\
\text { capillary roots } \rightarrow \\
\text { microscopic observation }\end{array}$ & $\begin{array}{l}\text { Normal pressure and } \\
\text { temperature }\end{array}$ & $\begin{array}{l}\text { Single layer, transparent, } \\
\text { visual, renewable, } \\
\text { wettability can be more } \\
\text { precise control, the earliest } \\
\text { seepage visualization in } \\
\text { China, size: } 140 \\
\text { longitudinal and } 140 \\
\text { transverse capillary } \\
\text { tubes each }\end{array}$ \\
\hline $\begin{array}{l}\text { Laser etching of glass } \\
\text { model }\end{array}$ & $\begin{array}{c}\text { Yu [32], Wu [33], Zhou } \\
\text { [34], Fan [24], Li [35,37], } \\
\text { Shi [36], } \\
\text { Espinola-Gonzalea [38], } \\
\text { Al-Ghanim [39], Wang } \\
\text { [40], Zhao [41], Feng [42], } \\
\text { Nie [43], Liu [44] et al. }\end{array}$ & $\begin{array}{l}\text { CT scan/casting section to } \\
\text { obtain core structure } \rightarrow \\
\text { laser etched glass } \rightarrow \\
\text { microscopic observation }\end{array}$ & $\begin{array}{l}\text { Normal pressure and } \\
\text { temperature }\end{array}$ & $\begin{array}{l}\text { It can truly reflect the pore } \\
\text { structure characteristics of } \\
\text { rock, and the gas and } \\
\text { water seepage can be } \\
\text { visualized, size: } 62.5 \mathrm{~mm} \\
\quad \times 62.5 \mathrm{~mm} \times 3.0 \mathrm{~mm}\end{array}$ \\
\hline Sanded glass model & Fang [45], Ye [46] et al. & $\begin{array}{l}\text { The upper and lower two } \\
\text { organic tempered glass, } \\
\text { sand filling in the middle } \\
\quad \rightarrow \text { observation }\end{array}$ & $\begin{array}{l}0.5 \mathrm{MPa}, \text { Normal } \\
\text { temperature }\end{array}$ & $\begin{array}{c}\text { Visualization, direct } \\
\text { observation, relatively } \\
\text { high pressure resistance, } \\
\text { relatively large model size } \\
(100 \mathrm{~mm} \times 100 \mathrm{~mm} \times \\
5.5 \mathrm{~mm})\end{array}$ \\
\hline Micro-fluidic chip & Guo [47], LYU [49] et al. & $\begin{array}{l}\text { 3D printed microfluidic } \\
\text { chip } \rightarrow \text { microscopic } \\
\text { observation }\end{array}$ & $\begin{array}{l}\text { Normal pressure and } \\
\text { temperature }\end{array}$ & $\begin{array}{l}\text { Gas and water have clear } \\
\text { outline and strong } \\
\text { contrast, size: } 2 \mathrm{~mm} \times \\
8 \mathrm{~mm} \times 6 \mathrm{~mm}\end{array}$ \\
\hline
\end{tabular}


Table 2. Cont.

\begin{tabular}{|c|c|c|c|c|}
\hline Experimental Model & Research Scholar & Experimental Method & Experiment Condition & Characteristic \\
\hline True core chip & Kong [50], Li [51] et al. & $\begin{array}{l}\text { The core is divided into } \\
\text { three sections. Two } \\
\text { sections are used for } \\
\text { various characterizations } \\
\text { and one section is used to } \\
\text { prepare real core slices } \\
\text { with a thickness of } \\
0.062 \mathrm{~cm}\end{array}$ & $\begin{array}{l}\text { Normal pressure and } \\
\text { temperature }\end{array}$ & $\begin{array}{c}\text { Real core, real pore } \\
\text { structure, model size: } \\
30 \mathrm{~mm} \times 20 \mathrm{~mm} \times \\
0.62 \mathrm{~mm}\end{array}$ \\
\hline $\begin{array}{l}\text { Core under magnetic } \\
\text { resonance imaging(MRI) }\end{array}$ & $\begin{array}{c}\text { Farahani [52], Xu [53], } \\
\text { Fernø [54], Wei [55], Tang } \\
\text { [56], Deng [57], } \\
\text { Hu [58] et al. }\end{array}$ & $\begin{array}{c}\text { Core plug } \rightarrow \text { test with } \\
\text { magnetic resonance } \\
\text { imaging }\end{array}$ & $\begin{array}{l}\text { Normal pressure and } \\
\text { temperature }\end{array}$ & $\begin{array}{l}\text { Real core, visualization of } \\
\text { gas-water distribution, } \\
\text { model size: diameter } \times \\
\text { length }=3.8 \mathrm{~cm} \times 5 \mathrm{~cm}\end{array}$ \\
\hline
\end{tabular}

\subsection{Physical Simulation Experiment Technique of Macroscopic Water Invasion Law}

For the effective development of edge and bottom water gas reservoirs, researchers have carried out a large number of physical simulation experiments on the law of water invasion, mainly using full-diameter cores to simulate the depletion development of edge and bottom water gas reservoirs under different water body sizes and different gas recovery rates, collecting pressure, flow rate and time measurements in the process of water invasion, and describing the law of water invasion by calculating the amount of water and the degree of recovery.

Table 3 shows the development of experimental model. Jiao [62], Fang [63], Liu [64,65] et al. studied the law of water invasion in the depletion production process of a bottom water gas reservoir by combining experimental and numerical simulation using a homogeneous full-diameter long core. Hu [23] and Shen [66] et al., facing the difficult problem of understanding the water invasion law for fractured-porous gas reservoirs and the mechanism affecting the recovery degree of gas reservoirs, made artificial fractures in the full-diameter sandstone columnar core, and then carried out experiments of water invasion, matrix absorption and its influence on the reservoir under the condition of penetrating horizontal fractures. It is considered that, in the process of water invasion, the edge and bottom water will burst rapidly along the fracture; at the same time, the reservoir matrix will absorb water, and the gas phase seepage channel will be reduced, thus increasing the gas phase percolation resistance of the reservoir matrix, reducing the stable production capacity of the gas reservoir and the final recovery degree. This mechanism reveals the main reason why the gas well production and final recovery degree decrease greatly after water invasion in fractured gas reservoir. It is still a difficult problem for researchers how to quantitatively fracture the core and test the permeability through indoor core experiments, and how to quantitatively analyze the contribution of fractures to gas reservoir permeability and gas well productivity. $\mathrm{Hu}$ [67], $\mathrm{Xu}$ [68] et al. adopted the method of quantitative fracture making in artificial cores and comprehensively considered the fracture scale (fracture height, fracture width and fracture penetration degree) to carry out the experimental test of gas permeability of the fractured core model and, respectively, studied the contribution to reservoir permeability under fracture penetration and non-penetration conditions. On the basis of experimental tests, the three factors of fracture conductivity, fracture communication ability and matrix gas supply capacity were comprehensively considered, establishing the mathematical evaluation model of fracture contribution to rock permeability and realizing the quantitative evaluation of fracture contribution to rock permeability. As shown in Figure 3, according to the geological characteristics of Chi 27 to Chi 39 well area in a carboniferous gas field in eastern Sichuan, a reservoir model composed of matrix reservoir and fractured-porous reservoir is established by using quantitative fracture-making technology. 
Table 3. Comparison of physical simulation experimental models and methods for macroscopic water invasion law.

\begin{tabular}{|c|c|c|c|}
\hline Experimental Model & Research Scholar & Experimental Method & Characteristic \\
\hline $\begin{array}{l}\text { Full diameter } \\
\text { columnar core }\end{array}$ & $\begin{array}{c}\text { Jiao [62], Fang [63], Liu [64,65], Hu } \\
{[23,67], \text { Shen [66], Xu [68] et al. }}\end{array}$ & $\begin{array}{c}\text { Pressure } \rightarrow \text { saturated gas } \rightarrow \\
\text { water connection } \rightarrow \text { depletion } \\
\text { mining with certain } \\
\text { production }\end{array}$ & $\begin{array}{l}\text { Artificial fracture making, } \\
\text { quartz filling, diameter } \times \\
\text { length }=10 \mathrm{~cm} \times 18 \mathrm{~cm} \text {, one } \\
\text { dimension, maximum } \\
\text { pressure is } 70 \mathrm{MPa}\end{array}$ \\
\hline $\begin{array}{l}\text { Multiple cores in series } \\
\text { and parallel }\end{array}$ & $\begin{array}{l}\text { Wang [69], Zhu [70], Hu [71-74], } \\
\text { Fang [75-77], Xu [78] et al. }\end{array}$ & $\begin{array}{c}\text { Pressure } \rightarrow \text { saturated gas } \rightarrow \\
\text { water connection } \rightarrow \text { depletion } \\
\text { mining with certain } \\
\text { production }\end{array}$ & $\begin{array}{c}\text { Quantitative fracture making, } \\
\text { single diameter } \times \text { length } 2.5 \\
\mathrm{~cm} \times 50 \mathrm{~cm} \text {, multi-point } \\
\text { pressure measurement, } \\
\text { two-dimensional, maximum } \\
\text { pressure is } 70 \mathrm{MPa}\end{array}$ \\
\hline
\end{tabular}

Pressure regulating valve

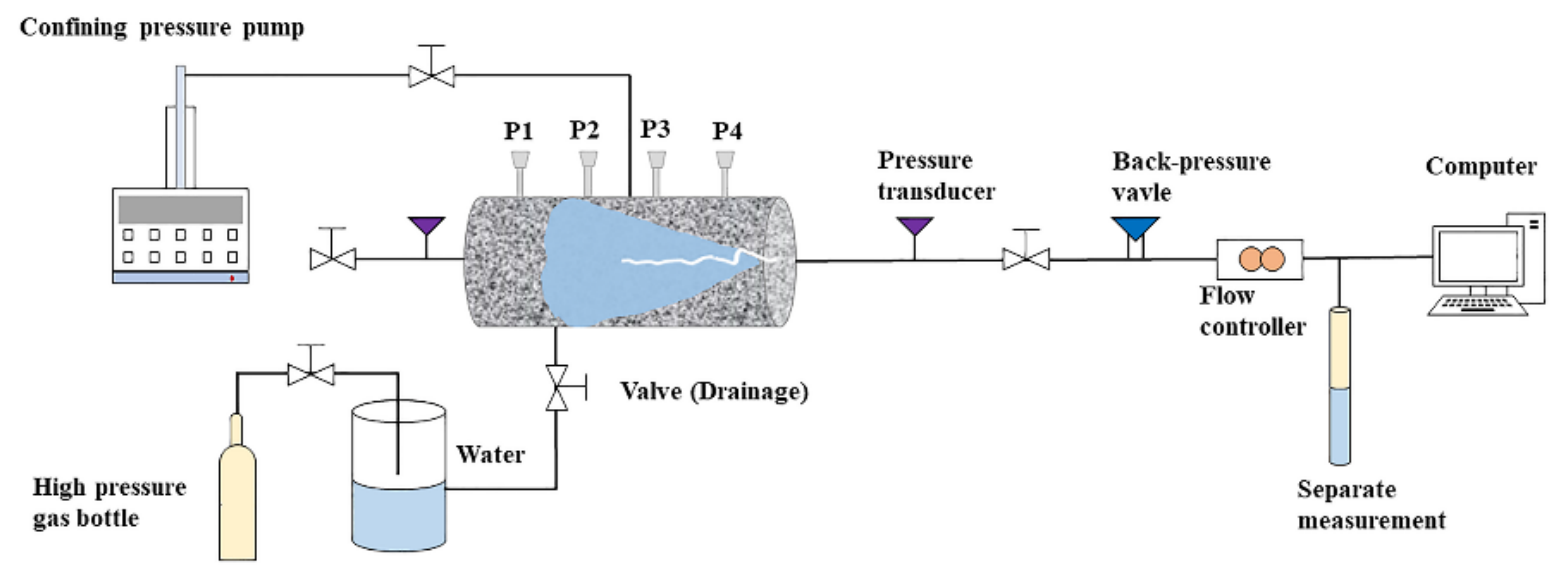

Figure 3. Experiment diagram of gas control drainage and drainage gas recovery in fractured-porous gas reservoir [68].

Most of the gas reservoirs are not single, but to study the condition of the multilayer, for the study of interlayer interference during multi-layer co-production, along with the gas supply characteristics and changes in productivity of s single gas reservoir, Wang [69], Zhu [70], Hu [71-74] et al. combined the geological characteristics and production conditions and established a dynamic physical model of gas supply for planar heterogeneous reservoirs by splicing cores with different permeabilities. Cores with different physical properties are connected in parallel and different simulation pressures are applied to simulate the formation of the multi-layer gas reservoir in order to establish a physical model of multi-layer co-production. Fang et al. [75-77] selected several cores to carry out series and parallel combination, and simulated the exploitation process of edge and bottom water gas reservoirs, as well as water invasion and the development of heterogeneous edge and bottom water gas reservoirs under different development modes. Xu et al. [78], based on the geological and development examples of chi 39 well block in Longdiao gas reservoir, produced three geological models of typical fractured water drive gas reservoirs to carry out physical simulation experiments of water invasion and water control, and used the dynamic production parameters, water invasion degree analysis, dynamic pressure drop profile, water saturation and surplus reserves distribution, developing five different methods to analyze and compare water invasion and development performance (Figure 4). 


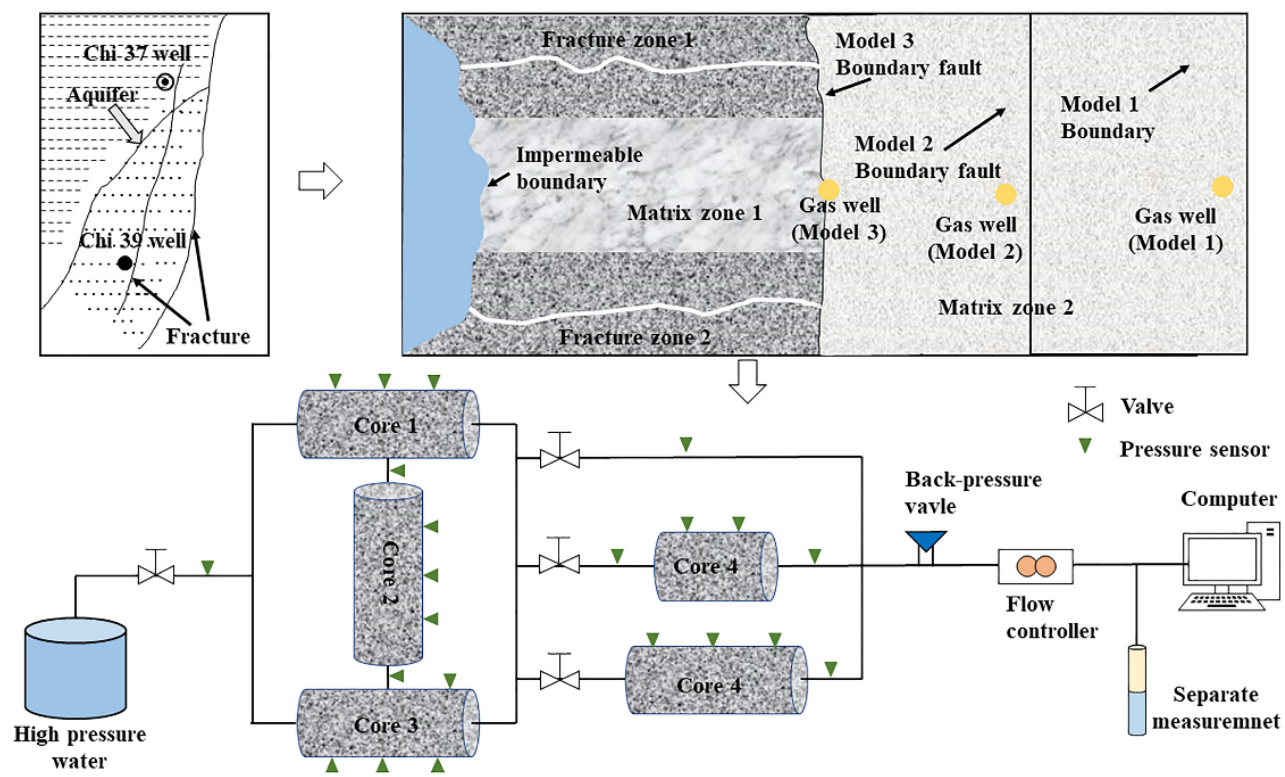

Figure 4. Geological models and schematic diagram of typical fractured water drive gas reservoirs (three geological models) [78].

With the development of experimental technology, model preparation and testing methods have comprehensively improved. On the one hand, the physical model has developed from a one-dimensional conventional scale into a two-dimensional model, which simulates more comprehensive geological and development conditions. On the other hand, the application of pressure field dynamic monitoring, NMR and resistivity saturation measurement technology makes the dynamic parameters obtained in the experiment more abundant. The progress of experimental technology has laid a foundation for the development of a comprehensive experimental analysis method for studying water invasion and development in the gas reservoir. When the research purpose is to study pressure change and water production in the process of water invasion of a single reservoir, full diameter columnar cores can be adopted. However, since most reservoirs are heterogeneous, several cores with different physical properties can be combined for experimental research. How to more accurately simulate the structure and edge and bottom water distribution of the gas reservoir, on the basis of the description of this more refined geological model, combined with the deployment and production characteristics of the well pattern of the gas reservoir, in order to establish a more realistic three-dimensional physical model, fully considering the difference between horizontal and vertical water invasion, and obtaining real-time acquisition of dynamic parameters such as model pressure field and water saturation field, will be the focus of the next step.

\section{Water Invasion Mechanism of Fractured-Porous Gas Reservoir}

On the basis of the development of this water invasion physical simulation experimental technology, the understanding of water invasion mechanisms of fractured-porous gas reservoirs has been continuously improved and deepened, and the research achievements of various scholars can be synthesized: due to the hydrophilicity and low seepage resistance of fractures, under a certain pressure difference water breaks through rapidly along the larger fractures, resulting in gas in the rock being separated by fractures into several units and forming a water seal. After water invasion of a relatively highly permeable large fracture, under the action of capillary force $[79,80]$ the water in the large fracture infiltrates into the matrix sealed by it. In the process of infiltration, in the narrow deformation of the pore throat and because of the Jamin effect, the continuous flow of gas will be blocked and some of the gas will be locked. At the same time, due to the hydrophilicity of the rock, the water flows along the pore throat surface, and when the water film continues to thicken 
and gather, part of the gas is locked, forming a water lock. The water seal reduces the flow between the units which are sealed by cracks, resulting in a decrease in gas production, while the water lock locks the gas inside each unit, further reducing gas production. In China, conventional proven reserves of natural gas generally occur in highly heterogeneous reservoirs with low porosity. More than $70 \%$ of domestic gas reservoirs are significantly affected by non-uniform water invasion, which leads to shortening of the stable production period and reduced oil recovery. Understanding of water intrusion mechanisms is the theoretical basis for improving oil recovery in water intrusion gas reservoirs. At present, the understanding of this water invasion mechanism is mainly qualitative. However, it is difficult to quantitatively describe and predict the non-uniform water invasion characteristics in a gas reservoir due to the influence of reservoir heterogeneity and elastic energy differences at different pressure stages during the development process. At the same time, it is difficult to quantitatively characterize the formation conditions of macroscopic water seal and microscopic water lock during gas reservoir development. Therefore, the author believes that the best future research direction is to combine core flow experiments with digital core flow simulation, so as to reveal the formation mechanism of gas reservoir water locks and water seals, to quantitatively evaluate the relationship between gas phase flow pressure difference of different types of reservoirs and saturation and thickness of the water-bearing area, and to establish a critical condition identification chart for gas reservoir water lock and gas seal formation, so as to provide theoretical guidance for early warning of water invasion in gas reservoirs.

\section{Development Countermeasures of Fractured-Porous Water-Bearing Gas Reservoirs}

There are three stages in the development of gas reservoirs with water: the water-free gas production period, gas production period with water and gas production period with water withdrawal. A large number of production practices have proved that the water-free gas production period is superior to thegas production period with water, where gas well production is relatively stable, and accumulated gas production is large [81]. In order to improve the recovery of a water-bearing gas reservoir, in the process of gas reservoir development all waterproof invasion and drainage measures should be taken to make full use of formation energy, optimize production performance and drainage methods, and avoid water invasion forming water seals and water locks, in order to prolong the anhydrous gas production stage, the period of self-injection gas production and the period of validity of the measures taken in gas wells, to effectively reduce production costs and improve development efficiency. In view of the fractured-porous water-bearing gas reservoir, based on this understanding of water invasion mechanisms, the author suggests that the influence of water invasion can be mitigated and controlled with relation to the following aspects:

(1) Controlling water to produce gas. Water-controlled gas production [82] has to take measures before the deployment of gas wells and during the period of water-free gas production to prevent edge and bottom water from rushing into the gas zone. In the deployment of gas wells for bottom water gas reservoirs, it is best to deploy gas producing wells at the high part of the structure. During perforation, the height of water avoidance should be raised away from the water body and the flow distance of water should be extended. Horizontal wells or highly deviated wells should be drilled at the top to reduce the production pressure difference and make the bottom water advance upwards uniformly. For gas reservoirs with edge water, a non-uniform well pattern is adopted to reduce the pressure of the edge gas well and make the edge water advance evenly and horizontally. When the gas well is put into production, a reasonable production rate should be set and adjusted regularly in the anhydrous gas production period, so as to control the production pressure difference, slow down the water invasion rate, and make the gas-water interface advance evenly. It can not only make use of the formation water to advance reasonably, but also can avoid this water bursting along the fracture and forming a water seal, so as to ensure maximum anhydrous gas production. 
(2) Gas well production with water withdrawal means that, when the water has broken through in the gas wells, it uses the water-producing gas well for active drainage to consume water energy, control water invasion by reducing the pressure difference between gas area and water area, and delay the advance of edge water and bottom water to adjust the advancing speed of the gas-water boundary, reducing the pressure of the water seal area, avoiding the acceleration of water invasion, reducing gas well abandonment pressure, effectively preventing premature water flooding of the gas reservoir, and achieving the purpose of improving the recovery of the gas reservoir. This is a more active method in dealing with the harm caused by the water outflow of the gas reservoir, a feasible measure based on development performance, and the main method for the exploitation of a fractured-porous gas reservoir. The combination of reducing the gas recovery rate and production with water withdrawal not only makes full use of formation energy, but also ensures the uniform advance of the gas-water interface.

(3) Dissolving water seals and water locks caused by water invasion in the reservoir. This is mainly through the injection of gas $\left(\mathrm{CO}_{2}\right.$ or $\left.\mathrm{N}_{2}\right)$ [83-89] into the formation to pass through the isolated gas area sealed by the water, forming flow channels again, and reducing the flow resistance of natural gas. Gas can enter the low permeability layer that water cannot; moreover, due to its compressibility and expansion, gas plays a role in plugging, assisting drainage, displacement, and gas lift when energy is released, which helps to overcome the constraint of capillary force, thus discharging reverse osmotic water and reducing the water locking effect [90-93]. When $\mathrm{N}_{2}$, which is twice the volume of water-flooded pore, was injected into the Medvezhye giant gas field in Russia for 13 consecutive years, $60 \%$ of the water-sealed gas was converted to free gas [94,95]. Of course, $\mathrm{CO}_{2}$ or $\mathrm{N}_{2}$ can also be partially dissolved in water under formation conditions, and studies have shown that the solubility of $\mathrm{CO}_{2}$ or $\mathrm{N}_{2}$ increases as the pressure increases, the concentration of $\mathrm{NaCl}$ in the aqueous phase decreases. Or the temperature decreases, and the solubility of $\mathrm{CO}_{2}$ is higher than $\mathrm{N}_{2}$ under the same conditions [96]. Therefore, further research is needed to determine which gas or gas mixture is more effective when injected in formation conditions. In addition to gas injection, methods such as annotating water locking agents [97-101] (surfactants, alcohols, ethers, acids, inorganic salts, etc.), acidifying the formation [91], injecting dry gas or preheating the formation by microwave heating [102] can also be used.

(4) Injecting gas to replenish energy. The principle of injection-production balance is used to replenish energy by injecting gas into the low-pressure free gas area and restoring gas well productivity so as to improve gas reservoir recovery.

There are some theoretical and numerical simulation studies [103-107] on the development strategies of the four water-bearing gas reservoirs above, but there are few experimental studies [84-89]. Therefore, on the basis of understanding the mechanisms and laws of water invasion, the next step in research on water-bearing gas reservoirs is to verify and optimize the development strategies of water-bearing gas reservoirs through physical simulation experiments.

\section{Conclusions and Prospects}

(1) Current research on water invasion mechanisms and new experimental techniques have limitations, i.e., how to truly simulate the structure of the gas reservoir, edge-bottom water distribution and the high temperature and high pressure environment, on the basis of a fine geological model, combined with the features of well pattern deployment and exploitation of the gas reservoir, in order to establish a more realistic three-dimensional physical model, giving full consideration to the difference between water along the lateral and longitudinal invasion, and real-time access to the dynamic parameters such as pressure and water saturation field of the model; these will be the difficulties that need to be overcome in the next step.

(2) When water invasion occurs in a fractured-porous gas reservoir, water first rushes along the larger fracture, resulting in gas in the reservoir being separated into several units 
by the fracture, and forming a water seal. After water invasion occurs in the big crack with relatively high permeability, under the effect of capillary force the water in the big fracture infiltrates into the matrix sealed by it. Because of the Jamin effect, the continuously flowing gas will be broken up and some gas will be locked. At the same time, because of the hydrophilic rock, the water will flow along the pore throat surface, and when the water film is thickened and gathered continuously, it will lock some gas and form a water lock. The production of the gas well is reduced by the macroscopic water sealing of the reservoir and the microcosmic water locking of the matrix. The understanding of current water invasion mechanisms is qualitative, and the future research direction is to combine core flow experiments with digital core flow simulation, so as to reveal the formation mechanism of gas reservoir water locking and gas reservoir water sealing, to quantitatively evaluate the relationship between gas phase flow differential pressure of different types of reservoirs and the water saturation and thickness of the water-bearing area, and to establish a critical condition identification chart for gas reservoir water locks and gas seal formation, so as to provide theoretical guidance for early warning of water invasion in gas reservoirs.

(3) Based on the understanding of water invasion mechanisms, development countermeasures for fractured-porous water-bearing gas reservoirs are put forward: watercontrolled gas production; gas well production with water withdrawal; dissolving water seals and water locks; and injecting gas to replenish energy.

Author Contributions: Conceptualization, M.Z., X.L. and Y.H.; methodology, Y.H. and Y.L.; validation, M.Z., X.L., X.X., L.J., Y.H. and Y.L.; formal analysis, X.X, L.J and Y.L.; investigation, M.Z. and L.J.; resources, X.L., Y.H. and X.X.; data curation, M.Z.; writing-original draft preparation, M.Z.; writing-review and editing, M.Z., X.L., X.X., L.J., Y.H. and Y.L.; visualization, M.Z., X.X. and L.J.; supervision, X.L., Y.H. and Y.L.; funding acquisition, X.L. and Y.H.; All authors have read and agreed to the published version of the manuscript.

Funding: This research was funded by the National Natural Science Foundation of China, grant number 51704326.

Institutional Review Board Statement: Not applicable.

Informed Consent Statement: Not applicable.

Conflicts of Interest: The authors declare no conflict of interest.

\section{References}

1. Jia, C.; Zhang, Y.; Zhao, X. Prospects of Challenges to Natural Gas Industry Development in China. Nat. Gas Ind. $2014,34,1-13$.

2. Li, X.; Guo, Z.; Hu, Y.; Luo, R.; Su, Y.; Sun, H.; Liu, X.; Wan, Y.; Zhang, Y.; Li, L. Efficient Development Strategies for Large Ultra-Deep Structural Gas Fields in China. Pet. Explor. Dev. 2018, 45, 111-118. [CrossRef]

3. Zhang, J.; Fang, F.; Lin, W.; Gao, S.; Li, Y.; Li, Q.; Yang, Y. Research on Injection-Production Capability and Seepage Characteristics of Multi-Cycle Operation of Underground Gas Storage in Gas Field-Case Study of the Wen 23 Gas Storage. Energies 2020, 13, 3829. [CrossRef]

4. Lu, J.; Zhao, S. Optimization of Energy Consumption Structure and Natural Gas Industry Development Prospect in China. Nat. Gas Ind. 2013, 33, 9-15.

5. Zou, C.; Zhao, Q.; Chen, J.; Li, J.; Yang, Z.; Sun, Q.; Lu, J.; Zhang, G. Natural Gas in China: Development Trend and Strategic forcast. Nat. Gas Ind. 2018, 38, 1-11. [CrossRef]

6. Shen, W.; Li, X.; Ma, T.; Cai, J.; Lu, X.; Zhou, S. High-Pressure Methane Adsorption Behavior On Deep Shales: Experiments and Modeling. Phys. Fluids 2021, 33, 063103. [CrossRef]

7. Dai, J.; Qin, S.; Hu, G.; Ni, Y.; Gan, L.; Huang, T.; Hong, F. Major Progress in the Natural Gas Exploration and Development in the past Seven Decades in China. Pet. Explor. Dev. 2019, 46, 1037-1046. [CrossRef]

8. Li, J.; Zheng, M.; Zhang, G.; Yang, T.; Wang, S.; Dong, D.; Wu, X.; Zhai, H.; Chen, X. Potential and Prospects of Conventional and Unconventional Natural Gas Resource in China. Acta Pet. Sinica 2012, 33, 89-98.

9. Zhang, J.; Liao, X.; Chen, Z.; Wang, N. A Global Search Algorithm for Determining Water Influx in Naturally Fractured Reservoirs. Energies 2019, 12, 2658. [CrossRef]

10. Wang, H.; Liu, Y.; Wang, F.; Wang, X.; Meng, W.; Zhang, J.; Pang, Y. Water Invasion Law in Deepsea Bottom-water Gas Reservoirs and a Water Invasion Risk Identification Method. Nat. Gas Ind. 2020, 40, 71-79. 
11. Fang, F.; Shen, W.; Li, X.; Gao, S.; Liu, H.; Li, J. Experimental Study on Water Invasion Mechanism of Fractured Carbonate Gas Reservoirs in Longwangmiao Formation, Moxi Block, Sichuan Basin. Environ. Earth Sci. 2019, 78, 316. [CrossRef]

12. Yan, W.; Qi, Z.; Yuan, Y.; Huang, X.; Li, J. Influencing Factor Analysis of Water Invasion in Condensate Gas Reservoir with Bottom Water Based on Fuzzy Comprehensive Evaluation and Orthogonal Experiment. Geosystem Eng. 2020, 22, 299-309. [CrossRef]

13. Huang, X.; Guo, X.; Zhou, X.; Shen, C.; Lu, X.; Qi, Z.; Xiao, Q.; Yan, W. Effects of Water Invasion Law on Gas Wells in High Temperature and High Pressure Gas Reservoir with a Large Accumulation of Water-Soluble Gas. J. Nat. Gas Sci. Eng. 2019, 62, 68-78. [CrossRef]

14. Hekmatzadeh, M.; Dadvar, M.; Emadi, M. Pore Network Modeling for Prediction of Residual Gas Saturation in Water Invasion Process. J. Porous Media 2014, 17, 503-520. [CrossRef]

15. Qi, Z.; Li, J.; Hu, S.; Liang, B.; Yuan, Y.; Jiang, N. Mathematical Model for Prediction of Dynamic Reserves Loss due to Water Invasion in Water-Drive Gas Reservoir. J. Porous Media 2019, 22, 1507-1518. [CrossRef]

16. Feng, X.; Peng, X.; Li, L.; Yang, X.; Wang, J.; Li, Q.; Zhang, C.; Deng, H. Influence of Reservoir Heterogeneity on Water Invasion Differentiation in Carbonate Gas Reservoirs. Nat. Gas Ind. 2018, 38, 67-75. [CrossRef]

17. Hu, S.; Li, J.; Jiang, N.; Yuan, Y.; Wan, X. Experimental Study on Dynamic Reserves Loss by Water Invasion in Water-driven Gas Reservoirs. Spec. Oil Gas Reserv. 2017, 24, 146-149.

18. Choi, J.-H.; Seol, Y.; Boswell, R.; Juanes, R. X-Ray Computed-Tomography Imaging of Gas Migration in Water-Saturated Sediments: From Capillary Invasion to Conduit Opening. Geophys. Res. Lett. 2011, 38, L17310. [CrossRef]

19. Tao, S.; Feng, X.; Xiao, S. Using Transient Testing to Identify Early Water Invasion of Gas Reservoirs. Nat. Gas Ind. 2003, 23, 68-70.

20. Li, X.; Lu, D.; Luo, R.; Sun, Y.; Shen, W.; Hu, Y.; Liu, X.; Qi, Y.; Guan, C.; Guo, H. Quantitative Criteria for Identifying Main Flow Channels in Complex Porous Media. Pet. Explor. Dev. 2019, 46, 943-949. [CrossRef]

21. Li, X.; Luo, R.; Hu, Y.; Xu, X.; Jiao, C.; Guo, Z.; Wan, Y.; Liu, X.; Li, Y. Main Flow Channel Index in Porous Sand Reservoirs and its Application. Pet. Explor. Dev. 2020, 47, 984-989. [CrossRef]

22. Sun, Z.D. Production Characteristics and the Optimization of Development Schemes of Fractured Gas Reservoir with Edge or Bottom Water. Pet. Explor. Dev. 2002, 4, 69-71.

23. Hu, Y.; Li, X.; Wan, Y.; Jiao, C.; Xu, X.; Guo, C.; Jing, W. The Experimental Study of Water Invasion Mechanism in Fracture and the Influence on the Development of Gas Reservoir. Nat. Gas Geosci. 2016, 27, 910-917.

24. Fan, H.; Zhong, B.; Li, X.; Liu, Y.; Yang, H.; Feng, X.; Zhang, Y. Studies on Water Invasion Mechanism of Fractured-Watered Gas Reservoir. Nat. Gas Geosci. 2012, 23, 1179-1184.

25. Davis, J., Jr.; Jones, S. Displacement Mechanisms of Micellar Solutions. J. Pet. Technol. 1968, 20, 1415-1428. [CrossRef]

26. Mast, R. In Microscopic Behavior of Foam in Porous Media. In Proceedings of the Fall Meeting of the Society of Petroleum Engineers of AIME, San Antonio, TX, USA, 8 October 1972.

27. Wardlaw, N. The Effects of Geometry, Wettability, Viscosity and Interfacial-Tension on Trapping in Single Pore Throat Pairs. J. Can. Petrol. Technol. 1982, 21, 21-27. [CrossRef]

28. Chatzis, I.; Morrow, N.R.; Lim, H.T. Magnitude and Detailed Structure of Residual Oil Saturation. SPE J. 1983, 23, 311-326. [CrossRef]

29. Morrow, N.R. Small-Scale Packing Heterogeneities in Porous Sedimentary Rocks. AAPG BULL 1971, 55, 514.

30. Guo, S.; Huang, Y.; Ma, X.; Zhou, J. Microscopic Research on Multiphase Flow through Porous Media. Acta Pet. Sin. 1984, 01, 59-66.

31. Qu, Z.; Kong, L. Study on the Formation of Residual Water with Transparent Porous Models. J. Pet. Technol. 1986, 01, 72-78.

32. Yu, J. Study on Seepage Mechanism and Simulation Theory and Method of Water Drive Gas Reservoir. Ph.D. Thesis, Southwest Petroleum Institute, Chengdu, China, 2005.

33. Wu, J.; Guo, J.; Zhao, J. Study on Gas/Water Two-Phase Percolation Mechanism for Fractured Formation. Nat. Gas Ind. 2004, 11, 85-87.

34. Zhou, K.; Li, N.; Zhang, Q.; Tang, X. Experimental Research on Gas-Water Two Phase Flow and Confined Gas Formation Mechanism. Nat. Gas Ind. 2002, S1, 122.

35. Li, D.; Zhang, L.; Zhou, K.; Guo, L. Gas-Water Two Phase Flow Mechanism in Visual Microscopic Pore Model. J. China Univ. Pet. Ed. Nat. Sci. 2008, 32, 80-83.

36. Shi, L.; Shao, L.; Wang, J.; Zhu, H. The Microscopic Mechanism of Operating Loss in Underground Gas Storage Rebuilt from Water-Drive Gas Reservoir. Oil Gas Storage Transp. 2018, 37, 658-663.

37. Li, Q.; Yang, Y.; Peng, X. In Research on Water Intrusion Mechanism and Water Control Countermeasures of Water-Bearing Gas Reservoirs in Sichuan Basin. In Proceedings of the 30th National Natural Gas Academic Annual Conference, Fuzhou, China, 21-23 September 2018.

38. Espinola-Gonzalez, O.; Guzman-Arevalo, J.; Ramirez-Cuacenetl, J.; Rocha-Carrascal, M.; Mehranfar, R. In Evaluation of Exploitation Strategies for Gas Reservoirs with Water Influx in the Miocene Formation of the Veracruz Basin Through Numerical Simulation to Optimize the Recovery Factor. In Proceedings of the SPE Trinidad and Tobago Section Energy Resources Conference, Port of Spain, Trinidad and Tobago, 13 June 2016.

39. Al-Ghanim, J.; Nashawi, I.; Malallah, A. In Prediction of Water Influx of Edge-Water Drive Reservoirs Using Nonparametric Optimal Transformations. In Proceedings of the SPE North Africa Technical Conference and Exhibition, Cairo, Egypt, 20 February 2012. 
40. Wang, L.; Yang, S.; Peng, X.; Deng, H.; Li, L.; Meng, Z.; Qian, K.; Wang, Q. Visual Experiments on the Occurrence Characteristics of Multi-Type Reservoir Water in Fracture-Cavity Carbonate Gas Reservoir. Acta Pet. Sin. 2018, 39, 686-696.

41. Zhao, X.; Ershaghi, I. In Production Geology as a Tool for Monitoring Water Influx in a Compartmentalized California Monterey Fractured Reservoir. In Proceedings of the SPE Western Regional Meeting, Anchorage, AK, USA, 23 May 2016.

42. Feng, X.; Yang, X.; Deng, H.; Chen, L.; Zhu, Z. Identification of the Water Invasion Law in High-Sulfur and Edge-Water Reservoirs Based on the Characteristics of Pressure Variation in the Zone. Nat. Gas Ind. 2013, 33, 75-78.

43. Nie, R.; Jia, Y.; Shen, N.; Qin, X.; Luo, X.; Zhang, W.; Liu, S. In A New Method to Discriminate Effectively the Influence of Water Injection and Natural Water Influx upon Reservoir Pressure System: A Case History from Cainan Oilfield. In Proceedings of the SPE Oil and Gas India Conference and Exhibition, Mumbai, India, 20 January 2010.

44. Liu, H.; Yang, S.; Zhang, J.; Deng, H. Study on Damage Mechanism of Solid Particle Plugging by Microvisual Model. Fault Block Oil Gas Field 2009, 16, 70-72.

45. Fang, F.; Li, X.; Gao, S.; Xue, H.; Zhu, W.; Liu, H.; An, W.; Li, C. Visual Simulation Experimental Study on Water Invasion Rules of Gas Reservoir with Edge and Bottom Water. Nat. Gas Geosci. 2016, 27, 2246-2252.

46. Ye, L.; Zhang, J.; Li, Q.; Gao, S.; Liu, H.; Zhu, W.; Xiong, W.; Xue, H. In Visualized Physical Simulation of Water Invasion Mechanism in Different Types of Edge and Bottom Water Gas Reservoirs. In Proceedings of the 2018 National Natural Gas Academic Conference, Fuzhou, China, 14 November 2018.

47. Guo, M.; Rotem, A.; Heyman, J.; Weitz, D. Droplet Microfluidics for High-Throughput Biological Assays. Lab A Chip 2012, 12, 2146-2155. [CrossRef] [PubMed]

48. Sinton, D. Energy: The Microfluidic Frontier. Lab A Chip 2014, 14, 3127-3134. [CrossRef]

49. Lyu, J.; Lu, X.; Wang, W.; Xie, K.; Hu, Y. Visual Test of Gas-water Distribution in Tight Sandstone Pores. Spec. Oil Gas Reserv. 2019, $26,136-141$.

50. Kong, L.; Qu, Z.; Wan, F.; Sun, W. Experiments of Two Fluid Phase Displacement in Sandstone Micromodels. Pet. Explor. Dev. 1991, 04, 79-85.

51. Li, T.; Xiao, W.; Li, M.; Wang, Y.; Ren, Y. Tests and Numerical Simulation for Microscopic Waterflooding in Sandstone Reservoirs. Spec. Oil Gas Reserv. 2017, 24, 155-159.

52. Farahani, M.H.; Guo, X.; Zhang, L.; Yang, M.; Hassanpouryouzband, A.; Zhao, J.; Yang, J.; Song, Y.; Tohidi, B. Effect of Thermal Formation/Dissociation Cycles on the Kinetics of Formation and Pore-Scale Distribution of Methane Hydrates in Porous Media: A Magnetic Resonance Imaging Study. Sustain. Energy Fuels 2021, 5, 1567. [CrossRef]

53. Xu, X.; Wan, Y.; Li, X.; Hu, Y.; Tian, S.; Mei, Q.; Jiao, C.; Guo, C. Microscopic imbibition characterization of sandstone reservoirs and theoretical model optimization. Sci. Rep. 2021, 11, 8509. [CrossRef]

54. Fernø, M.A.; Haugen, A.; Wickramathilaka, S.; Howard, J.; Graue, A.; Masom, G.; Morrow, N.R. Magnetic Resonance Imaging of the Development of Fronts During Spontaneous Imbibition. J. Pet. Sci. Eng. 2013, 101, 1-11. [CrossRef]

55. Wei, B.; Liu, J.; Zhang, X.; Xiang, H.; Zou, P.; Cao, J.; Bai, M. Nuclear Magnetic Resonance (NMR) Mapping of Remaining Oil Distribution during Sequential Rate Waterflooding Processes for Improving Oil Recovery. J. Pet. Sci. Eng. 2020, $190,107102$. [CrossRef]

56. Tang, H.; Zhu, B.; Wang, Q.; Zhang, L.; Zhao, F.; Wang, J. Mechanism and Control Factors of Water Blocking in Tight Sandstone Gas Reservoir. Sci. Sin. Tech. 2018, 48, 537-547. [CrossRef]

57. Deng, L.; Zhou, H.; Xue, D.; Sun, X.; Liu, Z. NMR-Based Characterization of Pore Structure and Nitrogen-Water Percolation in Coal. J. China Coal Soc. 2019, 44, 133-141.

58. Hu, Q.; Liu, S.; Yan, L.; Wang, H.; Fang, H.; Zhang, Q.; Mao, C.; Jia, M. Occurrence, Migration, and Output Path of Gas and Water in Anthracite Coal in Fanzhuang and Zhengzhuang Blocks. Saf. Coal Mines 2020, 51, 218-222.

59. Counsil, J.; Ramey, H. Effects of Vaporization and Temperature in Gas/Liquid Relative Permeability Experiments. Soc. Pet. Eng. J. 1982, 22, 108-116. [CrossRef]

60. Chen, Z.; Wu, X.; Fang, H.; Yang, W. Gas Transit Measurement Method of Permeability on Rock. Acta Geophys. Sin. 1999, S1, 167-171.

61. Fang, J.; Guo, P.; Xiao, X.; Du, J.; Dong, C.; Xiong, Y.; Long, F. Gas-Water Relative Permeability Measurement of High Temperature and High Pressure Tight Gas Reservoirs. Pet. Explor. Dev. 2015, 42, 84-87. [CrossRef]

62. Jiao, C.; Zhu, H.; Hu, Y.; Xu, X. The Physical Experiment and Numerical Model of Water Invasion to the Gas Reservoir. Sci. Tec. Eng. 2014, 14, 191-194.

63. Fang, F.; Shen, W.; Gao, S.; Liu, H.; Wang, Q.; Li, Y. Experimental Study on the Physical Simulation of Water Invasion in Carbonate Gas Reservoirs. App. Sci. Basel 2017, 7, 697. [CrossRef]

64. Liu, H.; Ren, D.; Gao, S.; Hu, Z.; Ye, L.; Liu, X. Water Influx Mechanism and Development Strategy of Gas Resrevoirs with Edge and Bottom Water. Nat. Gas Ind. 2015, 35, 47-53.

65. Liu, H.; Gao, S.; Ye, L.; Zhu, W.; An, W. Change Laws of Water Invasion Performance in Fractured-Porous Water-Bearing Gas Reservoirs and Key Parameter Calculation Methods. Nat. Gas Ind. 2020, 40, 90-99.

66. Shen, W.; Li, X.; Liu, X.; Lu, J.; Jiao, C. Physical Simulation of Water Influx Mechanism in Fractured Gas Reservoirs. J. Cent. South Univ. Sci. Technol. 2014, 45, 3283-3287. 
67. Hu, Y.; Mei, Q.; Chen, Y.; Guo, C.; Xu, X.; Jiao, C.; Jia, Y. In Study on Water Intrusion Mechanism and Control Technology of Fractured Edge and Bottom Water Gas Reservoir. In Proceedings of the 31st National Natural Gas Academic Conference, Hefei, China, 30 October 2019.

68. Xu, X.; Wan, Y.; Chen, Y.; Hu, Y.; Mei, Q.; Jiao, C. Physical Simulation of Water Invasion and Water Control for the Fractured Water-Bearing Gas Reservoirs. Nat. Gas Geosci. 2019, 30, 1508-1518.

69. Wang, L.; Yang, S.; Liu, Y.; Xu, L.; Deng, H.; Meng, Z.; Han, W.; Qian, K. Experiments on Gas Supply Capability of Commingled Production in a Fracture-Cavity Carbonate Gas Reservoir. Petrol. Explor. Develop. 2017, 44, 824-833. [CrossRef]

70. Zhu, H.; Hu, Y.; Zhu, W.; Wang, F.; Luo, R. Physical Simulation Technology for Gas Reservoir Development Behavior Analysis. Oil Drill. Prod. Technol. 2010, 32, 54-57.

71. Hu, Y.; Li, X.; Li, Y.; Xu, X.; Wang, J.; Jiao, C.; Guo, C. Enhanced Gas Recovery of the Law Permeability and Tight Sandstone Gas Reservior. Nat. Gas Geosci. 2015, 26, 2142-2148.

72. Hu, Y.; Yang, S.; Lu, Y.; Zhang, Y. Experimental Study on Occurrence Models of Water in Pores and the Influencing to the Development of Tight Gas Reservoir. Nat. Gas Geosci. 2011, 22, 176-181.

73. Hu, Y.; Zhu, H.; Chen, J.; Wan, Y.; Wang, S.; Luo, R.; Zhu, Q. Physical Simulated Study on the Gas -Supplying Mechanism of High-Low Permeable Serial -Connection-Formations. Nat. Gas Geosci. 2007, 03, 469-472.

74. Hu, Y.; Xu, X.; Li, J.; Wang, J.; Zhu, Q.; Xie, K.; Shi, L. The Experimental Research of Filling Gas Saturation in Sandstone Gas Reservior. Nat. Gas Geosci. 2016, 27, 1979-1984.

75. Fang, F.; Gao, S.; Liu, H. Simulation Experimental Study on Water Invasion Rules of Gas Reservoir with Multiwell Development. In Proceedings of the 2nd International Symposium on Computer Science and Intelligent Control, Stockholm, Sweden, 21-23 September 2018.

76. Fang, F.; Gao, S.; Liu, H.; Xiao, Q.; Ma, X.; Zhang, C. Experimental Simulation Study on Water Invasion Law of Gas Reservoir with Multiwell Development. Lab. Res. Explor 2019, 38, 42-45.

77. Fang, F.; Liu, H.; Xiao, Q.; Qing, H.; Yang, C. Experimental Simulation Study on Water Invasion Laws of Heterogeneous Gas Reservoir. Lab. Res. Explor. 2019, 38, 85-89.

78. Xu, X.; Mei, Q.; Chen, Y.; Han, Y.; Tang, H.; Jiao, C.; Guo, C. Experimental Analysis Method for Water Invasion and Development Performance of Gas Reservoir. Nat. Gas. Geosci. 2020, 31, 1355-1366.

79. Cieslinski, J.; Mosdorf, R. Gas Bubble Dynamics-Experiment and Fractal Analysis. Int. J. Heat Mass Transf. 2005, 48, 1808-1818. [CrossRef]

80. Zhang, L.; Feng, G.; Li, X. Water Breakthrough Simulation in Naturally Fractured Gas Reservoirs with Water Drive: Series B. J. Fluid Mech. 2005, 17, 466-472.

81. Li, C. Recovering Technology of Fractured and Watered Gas Reservoirs. Nat. Gas. Ind. 2003, S1, 123-126.

82. Li, J.; Chai, X.; Deng, C.; Pu, B.; Zhao, Y.; Li, R. Early-stage water control technology in improving the development efficiency of water drive gas reservoirs. Nat. Gas. Ind. 2017, 37, 132-139.

83. Adler, A.; Crawford, P. Nitrogen Injection into Water-Driven Natural Gas or Condensate Reservoirs Increases Recovery. In Proceedings of the 58th Annual Technical Conference and Exhibition, San Francisco, CA, USA, 5 October 1983.

84. Sang, D. Study on Two-Phase Seepage Mechanism of Gas-Water Mutual Flooding in the Process of Water Invasion in Puguang Gas Field. Ph.D. Thesis, Southwest Petroleum University, Chengdu, China, 2018.

85. Wu, Y. Experimental Study on Damage and Relief Method of Water Lock in Tight Sandstone Gas Reservoir of Ordos. Master's Thesis, China University of Petroleum, Beijing, China, 2018.

86. Bai, F. Analysis of Gas Reservoir Damage Factors and Method of Reducing Water Lock Damage in Su 6 Well Area. Master's Thesis, Xi'an Shiyou University, Xi'an, China, 2011.

87. Guo, C.; Li, H.; Tao, Y.; Lang, L.; Niu, Z. Water Invasion and Remaining Gas Distribution in Carbonate Gas Reservoirs Using Core Displacement and NMR. J. Cent. South Univ. Sci. Technol. 2020, 27, 531-541. [CrossRef]

88. Li, D.; Jiao, J.; Jiang, Z. Experimental Research of Injecting $\mathrm{N}_{2}$ in Reservoir with Water. Inn. Mong. Petrochem. Ind. 2012, 38, 1-3.

89. Dong, X. Study on EOR and Storage by $\mathrm{CO}_{2}$ Injection in the Middle and Late Period of Shallow Gas Reservoir Development. Master's Thesis, South Petroleum University, Chegndu, China, 2017.

90. Gao, Y.; Sun, L.; Zhang, Q.; Tang, Y.; Chen, B.; Wang, L.; Tian, C. Low Permeability Condensate Gas Well, Retrograde Condensate, Reverse Imbibition Damage and Removing Methods. J. Southwest Pet. Univ. Sci. Technol. Ed. 2005, 29, 45-49.

91. Zhong, X.; Huang, L.; Wang, L. New Advances in Seismic Geomorphology. Spec. Oil Gas. Reserv. 2008, $15,12-15$.

92. Zhou, X.; Sun, L.; Chen, C. Development and Method of Removing Retrograde Condensate and Water Blocking Impairment in the Low Permeability Condensate Gas Reservoir. Drill. Prod. Technol. 2005, 05, 66-68.

93. Zhou, X.; Sun, L.; Chen, C. Study on Water Lock Effect in Low Permeability Reservoir. Spec. Oil Gas. Reserv. 2005, 05, 52-54.

94. Li, S. Design of Gas Field Development Scheme; Petroleum Industry Press: Beijing, China, 2006.

95. Yang, Y.; Shen, G.; Song, W.; Guo, W.; Li, J. Nitrogen Injection Technique for Controlling Bottom Water Coning in Heavy Oil Reservoir. Pet. Geol. Recovery Effic. 2002, 03, 83-84.

96. Hassanpouryouzband, A.; Farahani, M.V.; Yang, J.; Tohidi, B.; Chuvilin, E.; Istomin, V.; Bukhaonov, B. Solubility of Flue Gas or Carbon Dioxide-Nitrogen Gas Mixtures in Water and Aqueous Solutions of Salts: Experimental Measurement and Thermodynamic Modeling. Ind. Eng. Chem. Res. 2019, 58, 3377-3394. [CrossRef] 
97. Li, N.; Wang, Y.; Zhang, S.; Li, J.; Zhang, Z.; Zhao, C.; Huang, W. Study on Water Block in Tight Sandstone Gas Reservoirs and Solutions Thereof. Drill. Fluid Complet. Fluid 2016, 33, 14-19.

98. Jiang, J. Study on Technology of Breaking Water Block in Later Stage of Gas Reservoirs Production in West Sichuan. Drill. Fluid Complet. Fluid 2012, 29, 64-66.

99. Yao, G.; Peng, H.; Lei, W.; Chen, H. Study on Unlocking Technology of Water-Lock in the Well of Low Permeability Gas Reservoir in the Mature Production Stage. Pet. Geol. Recovery Effic. 2011, 18, 97-99.

100. Yang, Y. Study of Water Locking Damage Mechanism and Water Unlocking of Low Permeability Reservoir. J. Southwest Pet. Univ. Sci. Technol. Ed. 2013, 35, 137-141.

101. Yan, F. Research and Application on Water Block Remover. Petrochem. Ind. Appl. 2018, 37, 75-78.

102. Li, G.; Meng, Y.; Tang, H. In Clean Up Water Blocking in Gas Reservoirs by Microwave Heating: Laboratory Studies. In Proceedings of the International Oil \& Gas Conference and Exhibition in China, Beijing, China, 5 December 2006.

103. Wan, X. Research of the Water Invasion Law and Water Control Measures in Main Reservoir of Puguang Gas Field. Master's Thesis, Chongqing University of Science and Technology, Chongqing, China, 2015.

104. Zhang, L.; Li, Y.; Zhou, Q. A new Method for Water Invasion Performance Prediction in the Early Stage of Fractured and Water-Carrying Gas Reservoir Development. J. Southwest Pet. Univ. Sci. Technol. Ed. 2007, 5, 82-85, $202-203$.

105. Zhang, L.; Mei, Q.; Li, Y.; Xu, B. The Method of Improving Recovery Efficiency of Edge Water Drive Gas Reservoirs. Nat. Gas. Ind. 2006, 11, 101-103.

106. Zhang, X. Study on Early Prediction Method of Water Invasion Dynamics in Fractured Water-Bearing Gas Reservoirs. Master's Thesis, Southwest Petroleum University, Chengdu, China, 2005.

107. Gu, S.; Zeng, D.; Sun, B.; Zhang, R.; Xu, Z. High Definition Water Intrusion Numerical Simulation of Puguang Gas Reservoir with Tens of Millions of Grid. Fault-Block Oil Gas. Field 2020, 27, 774-777. 